\title{
Estimating Net operating Income Growth for Modeling U.S. Apartment Property Capitalization Rates
}

\begin{abstract}
Executive Summary. The properties of income-to-price ratios in asset markets have potentially far reaching implications for understanding investor behavior. Prevailing levels of commercial real estate (CRE) capitalization rates, similar to price/earnings ratios for stocks and owner equivalent rent-to-price relatives for houses, may foretell future investment returns and income growth rates. In CRE capitalization rate models, rent growth rates often proxy for the net operating income (NOI) growth rates. Empirical studies of capitalization rate predictive powers produce inconsistent results that may be due either to the use of these rent growth proxies, model misspecification, or both. We use a novel approach for generating NOI growth rate estimates that involves combining survey rent and the expense growth rates for U.S. apartments. Our GARCH analysis of the capitalization rate spread process using the estimated NOI growth rate produces theoretically consistent results. Importantly, we demonstrate efficiency gains from using our NOI growth rate estimates relative to traditional rent growth rate.
\end{abstract}

\footnotetext{
* Konkuk University, Seoul, Korea or hsl3@konkuk.ac.kr.

** Cornell University, Ithaca, NY 14853 or jc81@cornell.edu.

*** Konkuk University, Seoul, Korea or ss244@konkuk.ac.kr.
}

\author{
by Hyun Seok Lee* \\ John B. Corgel ${ }^{* *}$ \\ Seungwoo Shin***
}

Commercial real estate (CRE) valuations and related financial analyses in many parts of the world rely heavily on the discounted cash flow (DCF) model. A basic version of the model incorporates the first moments of three random variablesexpected income-to-price ratio or capitalization rate, expected discount rate, and expected income growth rate-during holding periods theoretically as long as infinity. Many asset valuation studies focus on the probability distribution of the discount rate. These studies proceed under the assumption that the size and timing of future cash flows follow a deterministic or, more generally, a constant process, such as when future cash flows grow at a constant rate per annum. It is generally accepted, however, that cash flows available to service financial claims-net operating incomes (NOIs)—do not grow at either constant or deterministic rates. We feel that sharpening the research focus on the expected NOI growth process is timely for the advancement of $\mathrm{CRE}$ valuation modeling such that the distribution of the anticipated NOI growth rate is an essential model input.

Various studies of CRE valuation rely on the capitalization rate formulation proposed by Gordon (1962) and, because NOI data have not been available, authors will introduce the rent growth rate to proxy for the NOI growth rate. Some of this research (Hendershott and MacGregor, 2005; Clayton, Ling, and Naranjo, 2009: Plazzi, Torous, and Valkanov, 2010) devotes considerable attention to the income growth rate process. Only An and Deng 
(2009) and An, Deng, Fisher, and Hu (2012) model the income growth rate process using NOI data. ${ }^{1}$ Rent growth may be a good proxy for NOI growth when net rents prevail in the lease market as, for example, in the office rental market. In other market settings, such as for apartments, rent growth may not approximate NOI growth nearly as well. We propose a reasonable and cost effective way to estimate NOI growth rates by combining the expected rent growth rate and the expected operating expense growth rate from survey data. Although rent growth rates are shown to be a strong determinant of NOI growth rates, they are at best a reasonable approximation in cases in which net leases are not the norm (i.e., apartments and hotels).

We elect to work with financial information from apartment properties because gross rent is collected and the expenses paid by owners therefore play key roles in determining returns relative to other CRE property types. In this study, we follow the tradition in line with investor motivations of focusing on identification of the discount rate, but more intensively on the NOI growth rate. Our objective is to implement a method for specifying the NOI growth rate as a stochastic variable instead of a constant.

The study makes two important contributions to the literature. First, we provide an algorithm for joining expected rent growth rates and expected operating expense growth rates into NOI growth rates. These data are introduced into a GARCH $(1,1)$ model to explain the capitalization rate spread process using quarterly Real Estate Research Corporation (RERC) data from 1997:Q1 through 2012:Q3. Second, we show the efficiency gain from using the estimated NOI growth rate compared with the rent growth rate. We measure comparability of paired competing models using the closeness test from Vuong (1989).

The remainder of this paper is organized as follows. We first discuss the capitalization rate, the discount rate, and the NOI growth rate relationships and then present findings from related research. Second, we introduce the data and variable calculations with econometric model specifications and then explain our assumptions about the CRE market. Third, we report empirical findings and discuss the implications of these results. Concluding remarks appear in the final section.

\section{Related Research on Capitalization, Discount, and NOI Growth Rate Relationships}

Among the large number of studies that address both the synchronous and non-synchronous relationships between capitalization, discount, and income growth rates, we focus this review on findings that (a) directly apply to $\mathrm{CRE}$ valuation modeling and (b) make a contribution to improving knowledge about expected NOI growth rates. Collectively, previous studies do not present consistent empirical findings and conclusions about the direction and statistical significance of key inputs to the basic present value model.

Beginning with the seminal study by Wendt and Wong (1965) who first introduced the DCF model to real estate finance studies and extending out on the developmental spectrum to Campbell and Shiller (1989) who proposed an empirically testable log-linearization capitalization rate specification, the research related to ours fits into three streams. First, Clayton, Ling, and Naranjo (2009) follow a behavioral path by utilizing RERC survey data with a vector error correction model to analyze capitalization rate dynamics in tests for investor sentiment influences on CRE pricing. ${ }^{2}$ They believe the reason some studies report that the rent growth rate variable lacks significance in explaining capitalization rate dynamics comes from sentiment-laden rent growth rate data. They find some support for behavioral intervention, but rely on rent growth rates and capitalization rate levels in their model. We embark on a different path for explaining empirical inconsistencies in the related literature by modeling the capitalization rate spread process, incorporating our estimated NOI growth rates, and introducing a GARCH specification. The GARCH estimations allow us to analyze the variance in the capitalization rate spread process along with the mean results.

Second, we are not the first to model capitalization rate spreads using time series econometrics. 
Huang and Li (2010) decompose the apartment capitalization rate spread over the risk-free rate into local-fixed and time-variant components following Sivitanidou and Sivitanides (1999). They implicitly model NOI growth rates as a function of exogenous variables, such as supplygrowth and marketshare. Using metropolitan random-effect specification, they conclude that risk premiums in capitalization rates become disconnected from the fundamentals. Hendershott and McGregor (2005) also follow this tradition using an error correction model, finding the opposite result from Huang and Li (2010). In particular they show that U.K. property capitalization rates are linked to the anticipated rent growth rate in the expected manner. Plazzi, Torous, and Valkanov (2010) uniquely and explicitly model rent growth rates as an important dependent, endogenous variable after regressing rent growth on the lagged capitalization rate. ${ }^{3}$ They find that the capitalization rate marginally forecasts only the office rent growth rates among the major CRE property types.

The third relevant stream includes a methodological paper by An and Deng (2009). They present a dynamic capitalization rate model based on Campbell and Shiller (1989) that links the capitalization rate to multi-period expected returns and NOI growth rates. ${ }^{4}$ They analyze three variables simultaneously in a structural equation system and differentiate their system from those developed by Shilling and Sing (2007) and Plazzi, Torous, and Valkanov (2010). Despite the introduction of dynamic Gordon model specifications and vector autoregressive systems, empirical inconsistencies persist. Plazzi, Torous, and Valkanov (2010) find that capitalization rates have limited ability to predict rent growth, while An and Deng (2009) reach a different conclusion regarding the relationship between capitalization rates and NOI growth. Recently, An, Deng, Fisher, and Hu (2012) provide confirmation of the theoretically consistent result. We provide additional confirmation without relying on actual, and often proprietary, NOI data.

\section{Model and Variables}

Commercial real estate asset markets are generally characterized as illiquid, highly segmented, and informationally inefficient local settings in which heterogeneous properties trade with significantly large transaction costs and no short-sale provisions (Clayton, Ling, and Naranjo, 2009). Our capitalization rate measure is not from ex post contractual outcomes in this complex asset market. Instead, it represents the expectation of market participants regarding a one-year forward market equilibrium CRE asset value. Our NOI growth rate also is assumed to be the consensus estimate of market participants regarding the combined rent and operating expense growth rates in light of the one-year forward market equilibrium condition.

To construct a representative model of the discount rate for CRE investment, we assume an all-equity investment, which aligns with survey methodology. This means that changes in the capital markets, in particular the debt markets, are accommodated by changes in risk premiums made by unlevered investors as implicit costs.

By assumption, the CRE markets are informationally efficient only to the extent that survey respondents are well informed and generate rational expectations based on current information sets (i.e., relevant national and local market data). Our static Gordon (1962) model therefore is able to focus on efficient market behaviors as in long-run equilibrium.

\section{The Base Model}

Following Sivitanidou and Sivitanides (1999), we model the capitalization rate as:

$$
\text { cap rate }=\text { cap } \mathrm{rate}^{e}+\xi
$$

where the superscript $e$ indicates equilibrium.

They extend the model by incorporating a serial correlation coefficient $\rho$ to yield:

$$
\text { cap rate } \text { rap }_{t} \text { rate }_{t}^{e}+\rho \xi_{t-1}+\mathrm{v}_{t},
$$

where $\mathrm{v}_{t}$ represents an independent random shock. Huang and $\mathrm{Li}$ (2010) model the capitalization rate spread process in a similar fashion: 
cap rate spread $_{t}=$ cap rate spread $_{t}^{e}+\rho \xi_{t-1}+\mathrm{v}_{t}$.

Both Sivitanidou and Sivitanides (1999) and Huang and Li (2010) employ panel regression methods for model estimation. We model the capitalization rate spread in the same way as Huang and $\mathrm{Li}$ (2010) except for the use of a GARCH specification for model estimation instead of the panel regression. The difference in approaches is because we analyze U.S. apartment market time series data rather than a set consisting of many city markets. Specifically, we apply a GARCH $(1,1)$ specification to fit the capitalization rate spread to the discount rate and NOI growth rate proxies:

$$
\text { cap rate }=i r r-\text { noig }+\xi \text {, }
$$

where $\operatorname{irr}$ (i.e., discount rate) is the sum of the riskfree rate and risk premium and is the NOI growth rate.

The 10-year constant maturity Treasury bond rate serves as the risk-free rate such that a new equation becomes:

cap rate $=$ risk free + risk premium - noig $+\xi$.

Subtracting the risk-free rate from both sides of equation (5) simplifies to:

cap rate spread $=$ risk premium - noig $+\xi$.

The capitalization rate spread is explained in the estimating equation instead of the capitalization rate level because, as shown in Exhibit 1, the capitalization rate spread lacks a unit root while our testing indicates that the capitalization rate level has a unit root. This stability process property of capitalization rate spread is useful for applying closeness tests to competing models because it eliminates the need to fit either a vector autoregressive (VAR) or a vector error correction (VEC) model.

The GARCH specification provides two principle benefits. First, the capitalization rate spread is a

\section{Exhibit 1}

Unit Root Test: Capitalization Rate Spread Has

Unit Root

\begin{tabular}{llll}
\hline & Adj. $t$-Stat. & Prob. & Result \\
\hline Phillips-Perron test statistic & -2.52 & 0.11 & Accept at 10\% \\
Dickey-Fuller-GLS test statistic & -2.15 & 0.03 & Reject at 5\% \\
\hline
\end{tabular}

Note: The null hypothesis is that capitalization rate spread has unit root. The sources are the Federal Reserve Board and the Real Estate Research Corporation.

financial variable with a heteroscedasticity property, as indicated in Sivitanidou and Sivitanides (1999) and Huang and $\mathrm{Li}$ (2010). Second, GARCH makes it easier than with either a VAR or VEC model to calculate individual log-likelihood function values that are necessary to implement closeness tests. The GARCH $(1,1)$ specification is chosen among possible GARCH ( $p, q$, mean) specifications based on the log-likelihood ratio and GARCH model specification test results.

\section{The NOI Growth Rate}

The NOI growth rate is assumed to be an unknown function of both the rent growth rate and the operating expense growth rate, where rent is the market price of commercial space as determined by supply and demand conditions. Income growth in a Gordon-style model is the unencumbered rate of future financial flows to all capital suppliers after deduction of reoccurring operating expenses. For $\mathrm{CRE}$, the relevant income measure is NOI. For research purposes, the NOI growth rate has been estimated in a couple of different ways. First, it has been calculated using available rents and rent growth survey data, as in Hendershott and McGregor (2005) and Clayton, Ling, and Naranjo (2009). Second, it has been estimated from empirical specifications of structural models, as in Sivitanidou and Sivitanides (1999) and Huang and Li (2010). Sivitanidou and Sivitanides (1999), for example, use a structural form specification to implicitly model income growth rates using variables such as DRENT (i.e., rent growth) and INVAC (i.e., vacancy). Third, NOI growth rates have been calculated using actual NOIs earned in NCREIF property portfolios by An and Deng (2009) and An, Deng, Fisher, and $\mathrm{Hu}$ (2012). We employ a method 
for estimating NOI growth rates that does not exclusively rely on rents or realized NOIs, but instead comes from combining the rent and the expense growth rates found in subscriber survey data.

Our structural method for estimating the NOI growth rate has the form:

$$
\begin{aligned}
\text { noig }= & \Delta N O I / N O I \\
= & (\Delta \text { rent }-\Delta \text { expense }) /(\text { rent }- \text { expense }) \\
= & (\text { rentg } * \text { rent }- \text { expg } * \text { expense }) / \\
& (\text { rent }- \text { expense })
\end{aligned}
$$

where noig is the NOI growth rate, rentg is the rent growth rate, and expg is the expense growth rate. Let $q_{t}$ be the expense-to-rent ratio at time $t$. Then we have:

$$
\text { expense }_{t}=q_{t} * \text { rent }_{t} \text { for all } t \text {. }
$$

If we replace expense in equation (7) with rent* $q$, then the equation becomes:

$$
\begin{aligned}
\text { noig }= & (\text { rentg } * \text { rent }-(\operatorname{expg} * q * \text { rent })) / \\
& (\text { rent }-q * \text { rent }) \\
= & \left(\text { rentg }_{t}-\operatorname{expg}_{t} * q_{t}\right) /\left(1-q_{t}\right)
\end{aligned}
$$

To explain this in detail, we turn to the expense and rent ratio process, $q_{t}$. Let $q_{0}$ be an initial expense and rent ratio (i.e., 1996:Q4 in our data). Then we have:

$$
\begin{aligned}
q_{1} & =\text { expense }_{1} / \text { rent }_{1} \\
& =\text { expense }_{0}\left(1+\operatorname{expg}_{1}\right) / \text { rent }_{0}\left(1+\text { rentg }_{1}\right) \\
& =q_{0}\left(1+\operatorname{expg}_{1}\right) /\left(1+\text { rentg }_{1}\right) .
\end{aligned}
$$

Let $h_{t}$ be the ratio of $(1+\operatorname{expg})$ to $(1+$ rentg $)$ at time $t$. Then, equation (10) generalizes as follows:

$$
\begin{aligned}
q_{t}= & q_{0} \prod_{j=1}^{t} h_{j} \\
& \text { where } h_{j}=\left(1+\operatorname{expg}_{j}\right) /\left(1+\text { rentg }_{j}\right) .
\end{aligned}
$$

The NOI growth rate process now only depends on $q_{0}$, the rentg series, and the expg $_{t}$ series. At this point we do not fix $q_{0}$. Instead, we introduce three plausible levels for $q_{0}$ (i.e., $0.3,0.5$, and 0.7 ) to address the initial point problem. ${ }^{5}$ This means that $q_{0}$ depends on time, property type, and location. Our approach involves empirically testing the proposed specification set for $q_{0}$, along with the traditional proxies. We denote NOI growth rates based on each $q_{0}$ as noig3, noig5, and noig7, respectively.

Hereafter, noig 5 serves as the baseline ratio for the three estimated NOI growth rates needed when we create nested models. We use one nested model, rentg and noig5, as suggested by Vuong (1989).

\section{Empirical Analysis}

\section{Data and Descriptions}

Most of the data for this research come from Real Estate Research Corporation's RERC Real Estate Reports for the U.S. apartment property market over the period 1997:Q1 through 2012:Q3. Consistently administered surveys by RERC of several dozen institutional investors on U.S. real estate investment criteria began in $1989 .{ }^{6}$ Nearly the same information for nine property types became available in 1992 and then for large MSAs in 2000. These quarterly data include respondent estimates of initial and terminal capitalization rates, discount rate, investor sentiment index, expected holding period, and rent and expense growth rates.

Because rates of return and other information RERC publishes come from institutional investor surveys, these data have been somewhat underutilized for research purposes due to concerns about alignment of survey responses with marketbased outcomes. Clayton, Ling, and Naranjo (2009) perform comparative analyses of RERC rate data to Real Capital Analytics and National Council of Real Estate Investment Fiduciaries rates that come from property transactions. Correlation and regression results using these three series indicate that all are closely related through time, thus offering assurances that the RERC survey data reflect market transaction behaviors.

Also, we utilize as in Hendershott and McGregor (2005) the 10-year constant maturity Treasury 
Exhibit 2

Descriptive Statistics

\begin{tabular}{|c|c|c|c|c|c|c|}
\hline Variable & Remarks & Min & Max & Mean & $\sigma$ & C.V \\
\hline rentg & Rent growth rate & 0.012 & 0.04 & 0.028 & 0.007 & 0.250 \\
\hline expg & Expense growth rate & 0.025 & 0.03 & 0.029 & 0.002 & 0.069 \\
\hline noig3 & NOI growth rate at $q_{0}=0.3$ & 0.004 & 0.04 & 0.027 & 0.009 & 0.333 \\
\hline noig5 & $\mathrm{NOI}$ growth rate at $q_{0}=0.5$ & -0.007 & 0.04 & 0.026 & 0.013 & 0.500 \\
\hline noig7 & NOl growth rate at $q_{0}=0.7$ & -0.041 & 0.06 & 0.023 & 0.024 & 1.043 \\
\hline irr & Discount rate & 0.075 & 0.11 & 0.095 & 0.013 & 0.137 \\
\hline cap rate & Capitalization rate & 0.054 & 0.09 & 0.074 & 0.012 & 0.162 \\
\hline $10 y r t b$ & 10-year Treasury bond & 0.016 & 0.07 & 0.044 & 0.012 & 0.273 \\
\hline cap rate spread & Capitalization rate - 10-year Treasury bond & 0.006 & 0.05 & 0.03 & 0.009 & 0.300 \\
\hline risk premium & IRR - 10-year Treasury bond & 0.025 & 0.07 & 0.051 & 0.009 & 0.176 \\
\hline
\end{tabular}

Notes: For 1997:Q1-2012:03, there are 63 quarters of data for irr, cap rate, rentg, and expg, as well as for the 10-year Treasury rate. Apartment rent in RERC data comprises gross rent less free rent, tenant improvements, and commissions. The sources are the Bureau of Labor Statistics, Federal Reserve Board, and Real Estate Research Corporation.

bond rate data obtained from the FRB as the riskfree rate measure. Exhibit 2 provides descriptive statistics.

In a comparison of the coefficients of variation among the estimated NOI growth rates, rent growth rate indicates that rent growth has the lowest relative volatility and the NOI growth rates have larger coefficients of variation. We embrace the greater volatility of our estimated NOI growth rates to the extent that the measures may help explain CRE capitalization rate fluctuations more effectively than the smoother rent growth rate. The study period includes the "great recession" and financial crisis when market volatility increased and therefore higher volatility played a much more important role than in normal times.

Properties of the estimated NOI growth rate components, $q_{t}$ and $h_{t}$, are shown in Exhibit 3. The $q_{t}$ parameter follows a slight upward trend with a mean reverting behavior, while $h_{t}$ exhibits considerable stability. Exhibit 4 presents the time pattern for the three noig estimates and the rent growth rate. Visually, these variables appear highly correlated. Note that the volatility of the noig variable is proportional to $q_{0}$ because the denominator of noig is $1-q_{t}$ such that if $q_{t}$ goes to 1 then noig goes to infinity. Even noig3 is a more volatile income measure than the rent growth rate.
Exhibit 5 shows the expense growth rate time series, along with the rent growth rate and noig5. Professional management and the fixed expense component provide checks against extreme movements in apartment operating expenses; hence, the expense growth rate logically would be the least volatile of these series.

Considering that the correlation coefficient between noig5 and the rent growth rate equals 0.99 , as suspected from examining Exhibit 6, it would be logical to conclude that NOI growth rate and rent growth rate are interchangeable in empirical analyses. While the two series follow the same procyclical directions during up and down phases, our estimated NOI growth rates have an important point of differentiation from the rent growth rate. As displayed in Exhibit 5, near zero and negative NOI growth rates occurred during 2003 following the terrorism, economic, and health-related events of the prior two years and during the late-2000s financial crisis and great recession. The historical pattern of NOI growth rates more closely resembles the pattern of CRE asset prices than does the rent growth rate. This claim is supported by both the Real Capital Analytics and the CoStar repeat sale apartment subindexes, which slowed to near zero growth rates during the early 2000 s and declined in the late 2000 s. $^{7}$ 


\section{Exhibit 3 \\ $q_{t}$ and $h_{t}$ Time Series}

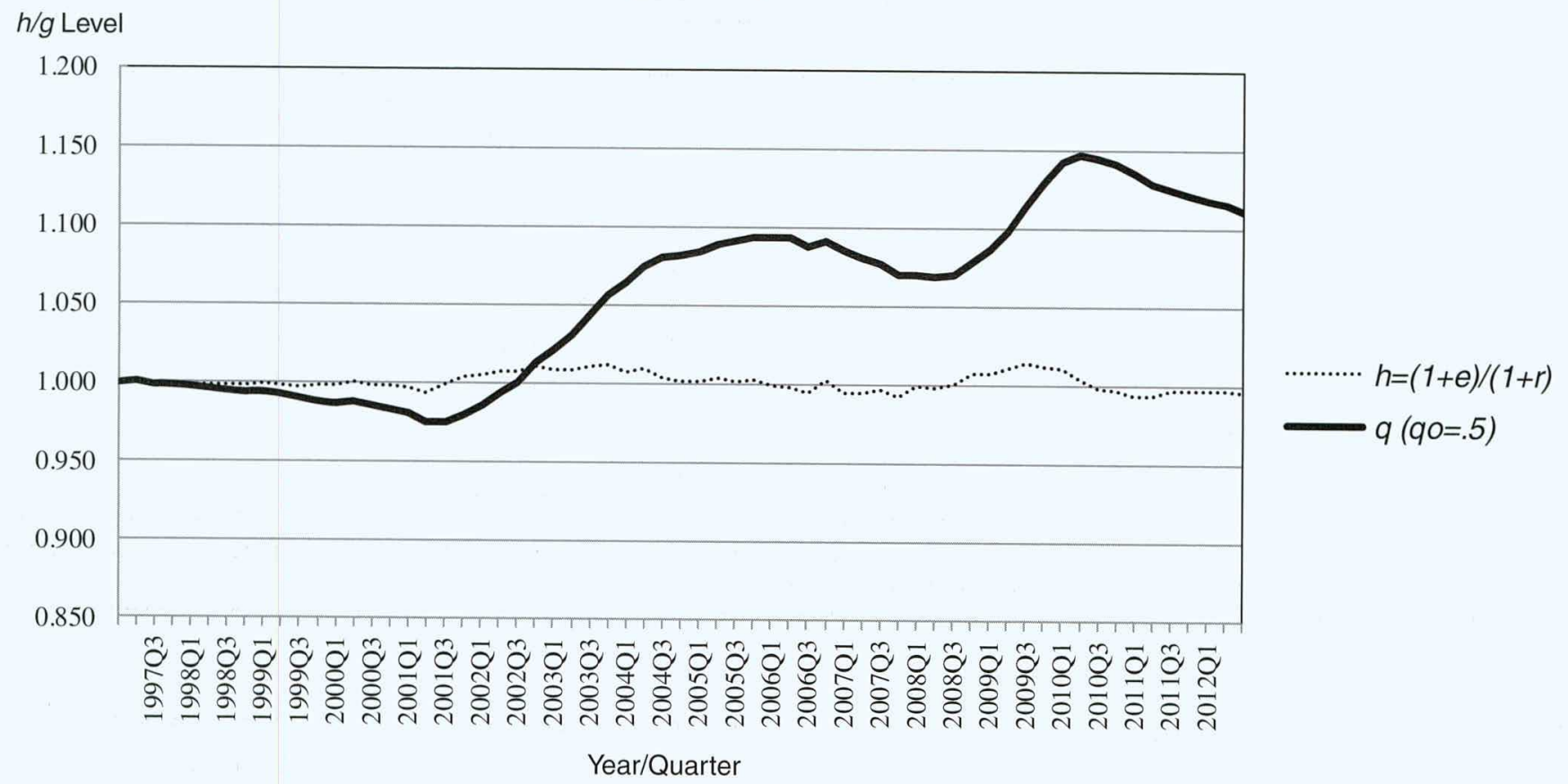

Note: In 1992:Q2, RERC started publishing apartment irr and capitalization rate data and added rent and expense rate data in 1997:01. The source is Real Estate Research Corporation.

\section{Exhibit 4}

Three Estimated NOI Growth Rates and Rent Growth Rate Time Series

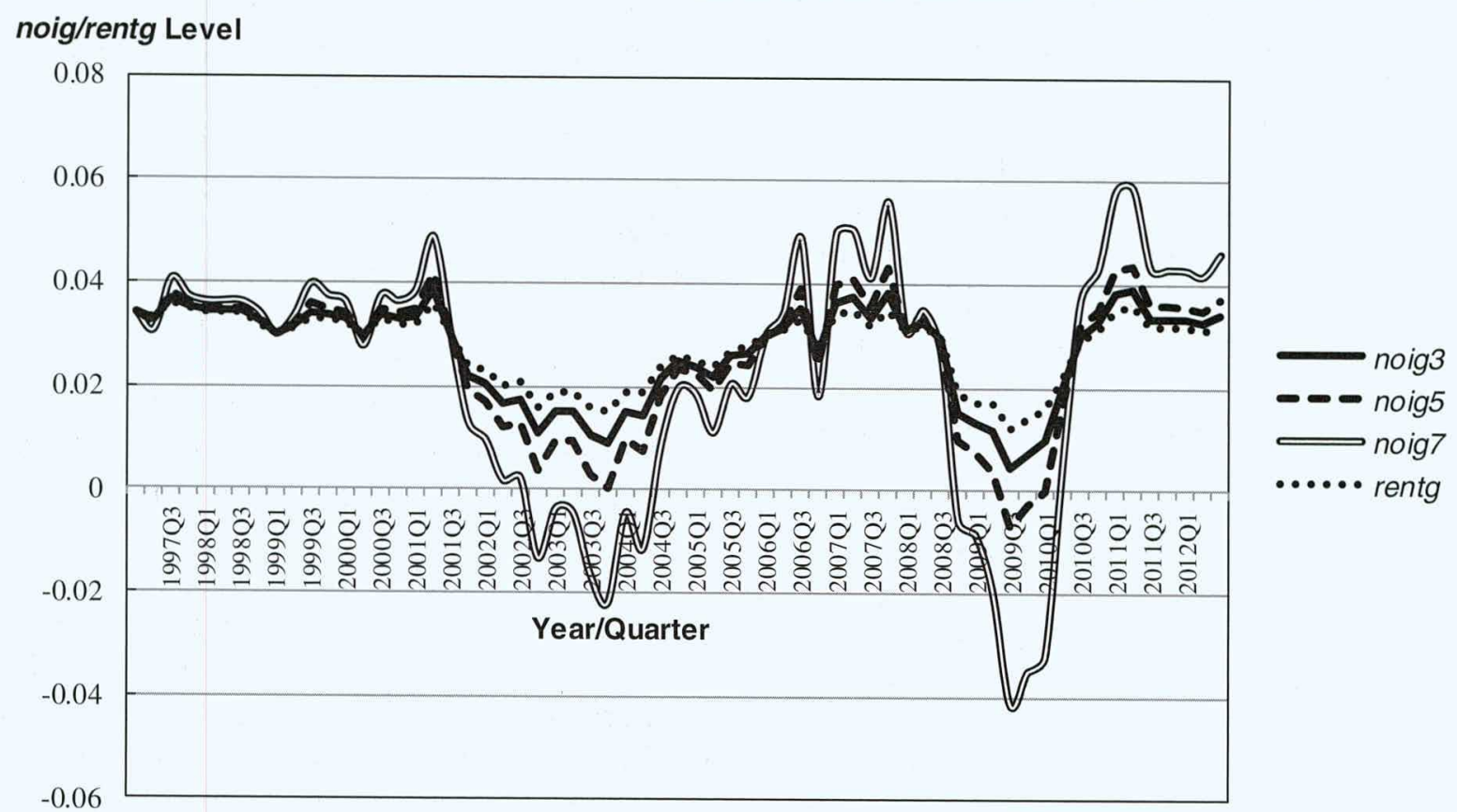

Note: In 1992:O2, RERC started publishing apartment irr and capitalization rate data and added rent and expense rate data in 1997:01. The source is Real Estate Research Corporation. 


\section{Exhibit 5 \\ Rent Growth Rate and Expense Growth Rate Time Series}

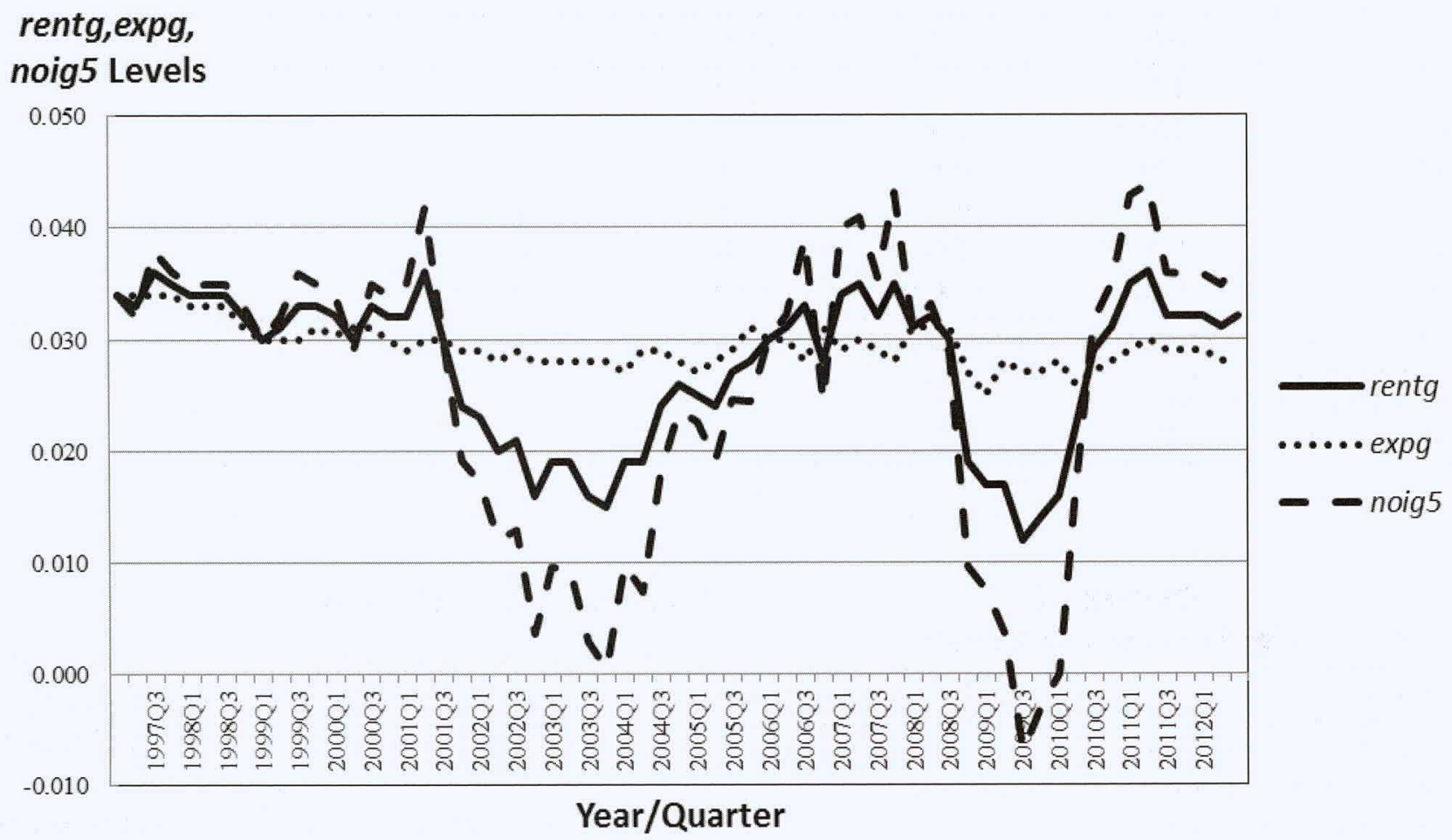

Note: In 1992:O2, RERC started publishing apartment irr and capitalization rate data and added rent and expense rate data in 1997: Q1. The source is Real Estate Research Corporation.

\section{GARCH Estimation Results}

We fit the eight competing capitalization rate spread models shown in Exhibit 7, each with a unique structure based on modeling variables discussed earlier. The parameter estimates for these models using a GARCH $(1,1)$ specification appear in Exhibit 8. All of the coefficients on the risk premiums and the NOI growth rate proxies conform to their theoretical signs and are significant at the $1 \%$ level, except for in the nested model.

In Exhibit 9, the eight competing models are ordered according to log-likelihood ratio and adjusted $\mathrm{R}^{2}$, respectively. This operation shows an almost perfect inverse relationship between the log-likelihood function value and adjusted $R^{2}$. Next, we select models for the closeness test based on both empirical and theoretical fit. Initially, the analysis is performed with a nested model because the test is easier to execute with nested models than with overlapping models. To correctly specify the nested model, the model must be superior to the smaller element model with respect to the loglikelihood function value (Vuong, 1989). Because the nested model, rentg and noig5, is inferior following log-likelihood function value criterion to the noig5 model, this nested model does not appear in Exhibit 9. Our experimentations indicate that the choice of $q_{0}$ does not change the results. Next, we choose rentg, noig3, noig5, and noig7 as default models for comparison purposes.

The rentg and expg model is the best model with respect to the adjusted- $R^{2}$ criterion, while it is the worst with respect to the log-likelihood function value. A competing model needs to be superior to the rentg model with respect to the log-likelihood function value criterion to align with our interest in seeing if the noig models prove superior after applying Vuong's (1989) tests. If we prove that all or part of our three noig models are superior to the rentg model in a closeness test sense, then we can recommend that practitioners and academic researchers adopt the proposed NOI growth rate estimation method. 


\begin{tabular}{|c|c|c|c|c|c|c|}
\hline & \multicolumn{5}{|c|}{$\begin{array}{l}\text { Exhibit } \mathbf{6} \\
\text { Pairwise Correlation }\end{array}$} & \multirow[b]{2}{*}{ cap rate spread } \\
\hline & noig3 & noig5 & noig7 & rentg & expg & \\
\hline noig3 & 1.00 & & & & & \\
\hline noig5 & $0.99 * * *$ & 1.00 & & & & \\
\hline noig7 & $0.99 * * *$ & $0.99 * * *$ & 1.00 & & & \\
\hline rentg & $0.99 * * *$ & $0.99 * * *$ & $0.97 * * *$ & 1.00 & & \\
\hline expg & $0.58^{* * *}$ & $0.53^{* * *}$ & $0.47 * * *$ & $0.64^{* * *}$ & 1.00 & \\
\hline cap rate spread & $-0.48^{* \star *}$ & $-0.47^{* * *}$ & $-0.45^{* * *}$ & $-0.49 * * *$ & $-0.36 * * *$ & 1.00 \\
\hline \multicolumn{7}{|c|}{$\begin{array}{l}\text { Notes: The sources are the Bureau of Labor Statistics, the Federal Reserve Board, and Real Estate Research Corporation. } \\
* \text { Significant at the } 10 \% \text { level. } \\
* * * \text { Significant at the } 5 \% \text { level. } \\
* * * \text { Significant at the } 1 \% \text { level. }\end{array}$} \\
\hline
\end{tabular}

\section{Exhibit 7}

\section{Eight Competing Models}

\begin{tabular}{ll}
\hline Common Variables & Modeling Variables \\
\hline cap rate spread $=$ risk premia $+\xi+$ & rentg \\
cap rate spread $=$ risk premia $+\xi+$ & rentg + expg \\
cap rate spread $=$ risk premia $+\xi+$ & noig3 \\
cap rate spread $=$ risk premia $+\xi+$ & noig5 \\
cap rate spread $=$ risk premia $+\xi+$ & noig7 \\
cap rate spread $=$ risk premia $+\xi+$ & AR (1) following Sivitanidou \\
cap rate spread $=$ risk premia $+\xi+$ & and Sivitanides (SS) \\
Lagged dependent variable & (LDV), cap rate spread \\
cate spread $=$ risk premia $+\xi+$ & rentg + noig5
\end{tabular}

Notes: We employ GARCH specification to fit all the competing specifications. The sources are the Federal Reserve Board and Real Estate Research Corporation.

The Sivitanidou and Sivitanides (1999) formulation identified as SS is discarded because it fails to dominate the noig5 model with respect to the log-likelihood function value. We also consider the lagged dependent variable (LDV) model, which is slightly superior to the noig5 model; however, the coefficient of the lagged dependent variable is not significant. Because of this inconsistency with the notion of adjustment to equilibrium, we eliminate the LDV model from further consideration.

Consequently, we are left with four competing models to test for closeness: rentg, noig3, noig5, and noig7.

\section{Closeness Test Results}

In this section we report closeness test results, which favor our proposed NOI growth rate. Vuong (1989) provides a theoretically and statistically rigorous comparison test of goodness-of-fit based on the log-likelihood ratio statistics. Vuong characterizes the asymptotic distribution of log-likelihood ratio statistics and makes it available for a binary competing models test under the most general conditions. The test involves two distinct test procedures, one for the nested models case and another for overlapping models case. We depart from the nested model cases because all variations proved inferior in preliminary screening as reported earlier. ${ }^{8}$ Intuitively, if hypothetical Model A, $f(y)$, theoretically dominates Model B model, $g(y)$, then it is reasonable to require that the log-likelihood ratio $f(y l s)<g(y l s)$, where $s$ is an explanatory variable and $y$ is the dependent variable. Generally, the closeness test method for overlapping models is equivalent to a difference of means test. To use an analogy, individual log-likelihood function value, $f_{i}(y l s)$, represents the measured height of a plant before the application of fertilizer, while the paired $g_{i}(y l s)$ represents the height of that plant after treatment.

The closeness test is guided by the following hypotheses:

$\mathbf{H}_{\mathbf{0}}$ : Models A and B are "equivalent."

$\mathbf{H}_{\mathbf{1}}$ : Model A is not "equivalent" to overlapping Model B. 


\section{Exhibit 8}

Estimation Results Using GARCH (1,1) Specification by EViews Procedures

\begin{tabular}{|c|c|c|c|c|c|c|c|c|}
\hline \multirow[b]{2}{*}{ Model } & \multicolumn{8}{|l|}{ Variable } \\
\hline & rentg & rentg $+\operatorname{expg}$ & noig3 & noig5 & noig7 & SS & LDV & rentg + noig5 \\
\hline risk premium & & & $\begin{array}{l}0.704^{\star * *} \\
(0.014)\end{array}$ & $\begin{array}{l}0.650^{* * *} \\
(0.009)\end{array}$ & $\begin{array}{l}0.628^{* * *} \\
(0.009)\end{array}$ & $\begin{array}{l}0.659 * * * \\
(0.027)\end{array}$ & $\begin{array}{l}0.651 * * * \\
(0.038)\end{array}$ & $\begin{array}{l}0.866^{* * *} \\
(0.033)\end{array}$ \\
\hline rentg & $\begin{array}{l}-0.287^{* * *} \\
(0.031)\end{array}$ & $\begin{array}{c}0.007 \\
(0.073)\end{array}$ & & & & & & $\begin{array}{c}-0.901 * * * \\
(0.155)\end{array}$ \\
\hline $\operatorname{expg}$ & & $\begin{array}{l}-0.511^{* * *} \\
(0.116)\end{array}$ & & & & & & \\
\hline noig3 & & & $\begin{array}{c}-0.215^{* * *} \\
(0.025)\end{array}$ & & & & & \\
\hline noig5 & & & & $\begin{array}{c}-0.112^{* * *} \\
(0.019)\end{array}$ & & $\begin{array}{c}-0.095^{* *} \\
(0.044)\end{array}$ & $\begin{array}{l}-0.107^{* * *} \\
(0.021)\end{array}$ & $\begin{array}{l}0.417 * * * \\
(0.103)\end{array}$ \\
\hline noig7 & & & & & $\begin{array}{c}-0.072^{\star * *} \\
(0.015)\end{array}$ & & & \\
\hline AR (1) & & & & & & $\begin{array}{l}0.574^{* * *} \\
(0.144)\end{array}$ & & \\
\hline cap rate spread $_{-1}$ & & & & & & & $\begin{array}{r}-0.005 \\
(0.063)\end{array}$ & \\
\hline$\omega$ & 0.001 & 0.001 & 0.001 & $0.001 * * *$ & 0.001 & 0.001 & 0.001 ** & 0.001 \\
\hline$\delta$ & $\begin{array}{c}0.153 \\
(0.445)\end{array}$ & $\begin{array}{c}0.272 \\
(0.240 \mid\end{array}$ & $\begin{array}{c}0.213 \\
(0.414)\end{array}$ & $\begin{array}{l}0.972 * * * \\
(0.296)\end{array}$ & $\begin{array}{c}0.227 \\
(0.288)\end{array}$ & $\begin{array}{c}0.114 \\
(0.104)\end{array}$ & $\begin{array}{l}0.948^{* *} \\
(0.421)\end{array}$ & $\begin{array}{c}0.319 \\
(0.254)\end{array}$ \\
\hline$\alpha$ & $\begin{array}{c}0.330 \\
(1.810)\end{array}$ & $\begin{array}{c}0.085 \\
(0.605)\end{array}$ & $\begin{array}{c}0.265 \\
(1.280)\end{array}$ & $\begin{array}{c}-0.429 * * * \\
(0.147)\end{array}$ & $\begin{array}{l}0.688^{* *} \\
(0.276)\end{array}$ & $\begin{array}{c}0.725^{*} \\
(0.396)\end{array}$ & $\begin{array}{c}-0.436^{* * *} \\
(0.163)\end{array}$ & $\begin{array}{c}0.087 \\
(0.505)\end{array}$ \\
\hline Log likelihood & 287.63 & 298.50 & 283.77 & 281.74 & 276.71 & 284.70 & 277.50 & 296.45 \\
\hline AIC & -8.97 & -9.28 & -8.85 & -8.78 & -8.62 & -8.99 & -8.75 & -9.22 \\
\hline Adj. $R^{2}$ & 0.91 & 0.93 & 0.89 & 0.87 & 0.86 & 0.91 & 0.87 & 0.92 \\
\hline
\end{tabular}

Notes: There are 63 quarters of data for 1997:01-2012:03. The dependent variable is cap rate spread. For GARCH (1,1), the variance equation is:

$$
\sigma_{t}^{2}=\omega+\alpha \xi_{t-1}^{2}+\delta \sigma_{t-1}^{2}
$$

Standard errors are in parentheses below the coefficients. The sources are the Federal Reserve Board and Real Estate Research Corporation. * Significant at the $10 \%$ level.

$* * *$ Significant at the $5 \%$ level.

*** Significant at the $1 \%$ level.

\section{Exhibit 9}

Model Ordering and Selection

\begin{tabular}{ll}
\hline & Order \\
\hline Log-Likelihood & noig7 $>$ LDV $>$ noig $5>$ noig3 $>$ SS $>$ rentg $>$ rentg + noig $5>$ rentg + expg \\
Adj. $\mathrm{R}^{2}$ & rentg + expg $>$ rentg + noig $5>$ SS $>$ rentg $>$ noig $>$ noig $>>$ LDV $>$ noig7 \\
\hline
\end{tabular}

Note: The AIC order is exactly the same as the log-likelihood function value order. The sources are the Federal Reserve Board and Real Estate Research Corporation. 
Exhibit 10

Closeness Test Results

\begin{tabular}{lllr}
\hline LR or LR/2 & noig3 vs. rentg & noig5 vs. rentg & noig7 vs. rentg \\
\hline$Z=L R /\left(\right.$ sqrt $\left.(n)^{*} \sigma\right)$ & & & 1.65 \\
Critical Level, 10\% & 1.65 & 1.65 & Reject Equivalence \\
Result & Reject Equivalence & Accept Equivalence & 44.87 \\
LR & 3.69 & 5.93 & 1.15 \\
STD & 0.27 & 0.84 & 15 \\
\hline
\end{tabular}

Notes: $L R=-\Sigma i=1 \mathrm{~N}\{\mathrm{MLEi}$, model $1-\mathrm{MLEi}$, model2\}, where model 1 is noig3 and Model 2 is rentg. A positive LR number means that Model 1 outperforms model 2. The LR result from Matlab of 3.69 differs from the EViews' MLE difference of 3.86 in the case of rentg vs. noig 3 due to the rounding error, which is intrinsic to Matlab procedures. However, in the noig 7 case, the difference is too great (44.87 vs. 10.92$)$, due to rounding-off error, which is intrinsic to Matlab procedures. STD = standard deviation of (MLEi, Model $1-$ MLEi, Model 2 ) series $Z$ statistics follow the standard normal distribution or $Z \sim N(0,1) n$ is the number of total time series, which is 63 quarters. The sources are the Federal Reserve Board and Real Estate Research Corporation.

Exhibit 10 presents the results of the closeness test. Both the noig3 and noig7 models are superior to the rent growth rate model. For the noig5 model, however, we cannot reject the null hypothesis. We need to explain the case of noig5, that is, the nonlinearity property in the Vuong's test results. Mathematically, the noig5 model estimation weakly improves the log-likelihood function value compared to the same measure for the noig 3 model from 3.69 to 5.93 , while the standard deviation measure noticeably increases from 0.27 to 0.84 .

In summary, the model with NOI growth rate only weekly improves capitalization rate spread modeling compared to a model with rent growth rate when $q_{0}$ is near 0.5 . Yet in experiments with $q_{0}$ different from 0.5 , we show considerably more relative improvement in a statistically rigorous sense. These results suggest that the choice of $q_{0}$ is critical for a particular property, property type, and geographic market to achieve an efficiency gain. For example, expense-to-rent ratio may be closer to 0.7 among aged apartment properties in older cities and closer to 0.3 for newly built apartments in high growth cities. In both these cases, our NOI growth rate estimating procedure would be superior to introducing the rent growth rate to a model intended either for valuation or prediction, particularly when NOI data are unavailable.

\section{Conclusion}

We present a reasonable and cost effective way to measure the NOI growth rate using rent growth rate and the operating expense growth rate from survey data. Although the rent growth rate is highly correlated with the NOI growth rate, it is at best a reasonable proxy. The correlation coefficient for the two series masks the extreme volatility of the NOI change during periods of financial distress. Rent changes follow a smooth path over time, while NOI changes reflect CRE investor pricing behavior both in theory and from recent experiences. The capitalization-rate spread modeling we perform based on GARCH confirms the theoretically correct result. Others recently achieve the same result using realized NOI data and a different modeling approach (An, Deng, Fisher, and $\mathrm{Hu}$, 2012). The estimated NOI growth rate variable improves the quality of model estimation results compared to the rent growth rate variable. The extent of the improvement depends on the relationship between operating expenses and rents and whether leases are gross, net, or non-existent. The more distant the market situation is from triplenet lease contractual arrangements in an average property market, the greater the efficiency gain from using NOI growth rates instead of rent growth rates in CRE financial modeling.

\section{Endnotes}

1. The NOI data applied in these studies come from NCREIF.

2. In the preliminary work performed for their study, Clayton, Ling, and Naranjo (2009) verify that capitalization rates coming from RERC surveys align closely in a statistical sense with capitalization rate series resulting from actual CRE transactions. 
3. They calculate NOI by multiplying the capitalization rate and transaction proceeds.

4. Sivitanidou and Sivitanides (1999), Huang and Li (2010), and ourselves use static Gordon models, while the dynamic version of the model adopts the process proposed by Campbell and Shiller (1989).

5 . We choose noig5 as our base case because both industry practitioners and academic researchers quote $q_{0}$ between 0.4 and 0.6, although this setting somewhat depends on time, property type, and location. Specifically, the IREM Income/ Expense Analysis Reports (2012) for conventional apartments shows that $q_{t}$ is between 0.451 and 0.519 using 20082011 data.

6. RERC reports the names of only those institutional investors who wish to be identified. The reported list equals about 25 well-respected real estate firms.

7. See https://www.rcanalytics.com/Public/rca_cppi.aspx and http://www.costar.com/about/CCRSI.aspx.

8. To use the nested alternative, the larger nesting model must be correctly specified. In other words, the nested model must have a superior log-likelihood function value.

\section{References}

An, X. and Y. Deng. A Structural Model for Capitalization Rate. Research report, Real Estate Research Institute, 2009.

An, X., Y. Deng, J.D. Fisher, and M.R. Hu. Commercial Real Estate Rental Index: A Dynamic Panel Data Model Estimation. Working paper, SSRN \#22050058, 2012.

Campbell, J.Y. and R.J. Shiller. The Dividend-Price Ratio and Expectations of Future Dividends and Discount Factors. Review of Financial Studies, 1989, 1:3, 195-228.
Clayton, J., D.C. Ling, and A. Naranjo. Commercial Real Estate Valuation: Fundamentals versus Investor Sentiment. Journal of Real Estate Finance and Economics, 2009, 38:1, 537.

Gordon, M. The Investment, Financing, and Valuation of the Corporation. Homewood, IL: R.D. Irwin, 1962.

Hendershott, P.H. and B.D. MacGregor. Investor Rationality: Evidence from U.K. Property Capitalization Rates. Real Estate Economics, 2005, 33:2, 299-322.

Huang, H. and X. Li. Efficient Market or Myopic Investors? Apartment Cap Rate Spread Decomposed. Working paper, Property and Portfolio Research, 2010.

Institute of Real Estate Management. Income/Expense Analysis: Conventional Apartments. Chicago, IL, 2012.

Plazzi, A., W. Torous, and R. Valkanov. Expected Returns and Expected Growth in Rents of Commercial Real Estate. Review of Financial Studies, 2010, 23:9, 3469-3519.

Shilling, J. and T.F. Sing. Do Institutional Real Estate Investors have Rational Expectations? Asian Real Estate Society Annual Conference, 2007.

Sivitanidou, R. and P. Sivitanides. Office Capitalization Rates: Real Estate and Capital Market Influences. Journal of Real Estate Finance and Economics, 1999, 18:3, 297-322.

Vuong, Q.H. Likelihood Ratio Tests for Model Selection and Non-nested Hypotheses. Econometrica, 1989, 57:2, 307-33.

Wendt, P.F. and S.S. Wong. Investment Performance: Common Stocks versus Apartment Houses. Journal of Finance, 1965, 20 : $4,633-46$.

Helpful comments and suggestions were provided by several reviewers. 